\title{
Local stress state of materials with an hcp lattice and plastic zones under the fracture surface
}

\author{
G. V. Klevtsov ${ }^{\dagger, 1}$, R.Z. Valiev², N.A. Klevtsova ${ }^{1}$, I. P. Semenova ${ }^{2}$, \\ I. N. Pigaleva ${ }^{1}$, M. L. Linderov ${ }^{1}$ \\ †Klevtsov11948@mail.ru
}

\author{
${ }^{1}$ Togliatti State University, 14 Belorusskaya St., Togliatti, 445020, Russia \\ ${ }^{2}$ SRI Physics of Advanced Materials, Ufa State Aviation Technical University, 3 K. Marx St., Ufa, 455000, Russia
}

\begin{abstract}
The work is aimed at establishing a relationship between the criteria for estimating the local stress state $h_{\max } / t$ (where $h_{\max }$ is the maximum depth of the plastic zone under the fracture surface, $t$ is the thickness of the sample or part) and the criterion of fracture mechanics $t /\left(K_{1 \mathrm{C}} / \sigma_{0.2}\right)^{2}$ for materials with an hcp lattice. The titanium alloys Ti-6Al-4Mo and Ti-6Al-4V were investigated in the initial coarse-grained (CG) and ultrafine-grained (UFG) states. The UFG state was processed by rotary forging (RF) in Ti-6Al-4Mo alloy and by equal-channel angular pressing (ECAP) and ECAP followed by isothermal forging (IF) in Ti-6Al-4V alloy. Testing of alloys for static crack resistance $\left(K_{1 \mathrm{C}}\right)$ was carried out on prismatic specimens with a thickness of $10 \mathrm{~mm}$ according to the three-point bending scheme in a liquid nitrogen environment $\left(-196^{\circ} \mathrm{C}\right)$. The depth of the plastic deformation zones under the fracture surfaces was determined by the X-ray method. The test results showed that UFG alloys had a lower $K_{1 \mathrm{C}}$ value than the alloys in the CG state. According to the criterion $t /\left(K_{1 \mathrm{C}} / \sigma_{0.2}\right)^{2}>2.5$, the fracture of all samples occurred under plane strain (PS) condition. According to the criterion $h_{\max } / t<10^{-2}$, only samples with the UFG structure were fractured under PS conditions. Analysis of the graphical dependence, reflecting the relationship of the criteria $t /\left(K_{1 \mathrm{C}} / \sigma_{0.2}\right)^{2}$ and $h_{\max } / t$ for titanium alloys Ti-6Al-4Mo and Ti-6Al-4V showed that for materials with an hcp lattice, the PS condition can be written as $t /\left(K_{1 \mathrm{C}} / \sigma_{0.2}\right)^{2} \geq 10$.
\end{abstract}

Keywords: UFG and CG titanium alloys, local stress state, static crack resistance $\left(K_{1 \mathrm{C}}\right)$.

УДК: 621.7(07)

\section{Локальное напряженное состояние материалов с ГПУ решеткой и пластические зоны под поверхностью изломов}

\author{
Клевцов Г.В. ${ }^{\dagger}$, , Валиев Р. 3. ${ }^{2}$, Клевцова Н. А. ${ }^{1}$, Семенова И. П. ${ }^{2}$, \\ Пигалева И.Н. ${ }^{1}$, Линдеров М. Л. ${ }^{1}$ \\ ${ }^{1}$ Тольяттинский государственный университет, ул. Белорусская, 14, Тольятти, 445020, Россия \\ ${ }^{2}$ НИИ Физики перспективных материалов УГАТУ, ул. К. Маркса, 3, Уфа, 455000, Россия
}

Работа посвящена установлению связи критериев оценки локального напряженного состояния $h_{\max } / t$ (где $h_{\max }-$ максимальная глубина пластической зоны под поверхностью излома, $t$ - толщина образца или детали) и критерия механики разрушения $t /\left(K_{1 \mathrm{C}} / \sigma_{0.2}\right)^{2}$ для материалов с ГПУ решеткой. Исследовали титановые сплавы Тi-6Al-4Mo и Ti-6Al-4V в исходном крупнозернистом (КЗ) и в ультрамелкозернистом (УМЗ) состояниях. УМ3 состояние сплава Ti-6Al-4Мо было получено путем ротационной ковки (РК); сплава Ti-6Al-4V - путем равноканального углового прессования (РКУП) и путем РКУП + изотермическая осадка (ИЗТО). Испытание сплавов на статическую трещиностойкость $\left(K_{1 \mathrm{c}}\right)$ проводили на призматических образцах толщиной 10 мм по схеме трехточечного изгиба в среде жидкого азота $\left(-196^{\circ} \mathrm{C}\right)$. Глубину зон пластической деформации под поверхностью изломов определяли рентгеновским методом. Результаты испытаний показали, что УМЗ сплавы обладают более низким значением $K_{1 C^{\prime}}$ чем сплавы в КЗ состоянии. Согласно критерию $t /\left(K_{1 \mathrm{C}} / \sigma_{0.2}\right)^{2}>2.5$, разрушение всех образцов произошло в условиях 
плоской деформации (ПД). Однако, согласно критерию $h_{\max } / t<10^{-2}$, в условиях ПД разрушились только образцы с УМЗ структурой. Анализ графической зависимости, отражающей связь критериев $t /\left(K_{1 \mathrm{C}} / \sigma_{0.2}\right)^{2}$ и $h_{\text {max }} / t$ для титановых сплавов Ti-6Al-4Mo и Ti-6Al-4V показал, что для материалов с ГПУ решеткой условие ПД можно записать в виде $t /\left(K_{1 \mathrm{C}} / \sigma_{0.2}\right)^{2} \geq 10$.

Ключевые слова: УМЗ и КЗ титановые сплавы, локальное напряженное состояние, статическая трещиностойкость $\left(K_{1 \mathrm{C}}\right)$.

\section{1. Введение}

Оценка локального напряженного состояния материала у вершины трещины имеет принципиальное значение, например, при испытании материалов на статическую трещиностойкость $\left(K_{1 \mathrm{c}}\right)$ в условиях плоской деформации (ПД) $[1,2]$, в том числе и материалов с УМЗ структурой [3-6]. Не менее важна такая оценка и при диагностике причин аварийного разрушения конструкций и деталей машин, когда необходимо соблюдение подобия по локальному напряженному состоянию материала в разрушенной детали и имитирующем образце $[7,8]$, а также в ряде других случаев.

Согласно положению механики разрушения, наиболее объективную информацию о локальном напряженном состоянии материала в момент разрушения дает анализ размеров и формы пластических зон, образующихся у вершины трещины $[1,2,9]$. Различают два предельных значения локального напряженного состояния материала: плоскую деформацию (ПД) и плоское напряженное состояние (ПН) $[1,2,9]$. Однако на практике разрушение металлических материалов нередко происходит в переходной области (ПД $П Н)[8,10]$. В работах $[8,11,12]$ было показано, что разрушение металлических материалов в условиях ПД сопровождается образованием у вершины трещины одной пластической зоны, а в условиях ПН - двух пластических зон: слабодеформированной макрозоны $\left(h_{y}\right)$ и сильнодеформированной микрозоны $\left(h_{y h}\right)$. В переходной области (ПД↔ПН) под поверхностью изломов также выявляются две пластические зоны, однако не всегда представляется возможным разделить макро- и микрозону $[8,12,13]$. Принимая во внимание важность такого параметра как размер пластической зоны в работах $[6,8,11,13,14]$ предложен количественный критерий оценки локального напряженного состояния материала как отношение максимальной глубины пластической зоны под поверхностью изломов $h_{\max }$ к толщине образца или детали $t$, т.е. $h_{\max } / t$. Если разрушение произошло в условиях ПД, то $h_{\max } / t<10^{-2}$; если в условиях $П Н$, то $h_{\text {max }} / t>10^{-1}$; если в переходной области $(П Д \leftrightarrow П Н)$, то $10^{-2} \leq h_{\max } / t \leq 10^{-1}$. Однако определять глубину пластических зон под поверхностью изломов, например, рентгеновским методом, - это длительный и трудоемкий процесс. Поэтому в работах $[15,16]$ установлена связь критерия $h_{\max } / t$ с известным критерием механики разрушения $t /\left(K_{1 \mathrm{C}} / \sigma_{0.2}\right)^{2}$ как для крупнозернистых (К3), так и для УМЗ материалов с ОЦК и ГЦК решеткой. В частности показано, что для материалов с ОЦК решеткой условия ПД реализуется при $t /\left(K_{1 \mathrm{C}} / \sigma_{0.2}\right)^{2} \geq 5.0$, а для материалов с ГЦК решеткой - при $t /\left(K_{1 \mathrm{C}} / \sigma_{0.2}\right)^{2} \geq 10$. Для материалов с ГПУ решеткой такая связь не установлена.

Целью настоящей работы является установление связи критериев оценки локального напряженного состояния $h_{\max } / t$ и $t /\left(K_{1 \mathrm{C}} / \sigma_{0.2}\right)^{2}$ для КЗ и УМЗ материалов c ГПУ решеткой на примере титановых сплавов Ti-6Al-4Mо и Ti-6Al-4V.

\section{2. Материалы и методики исследования}

В качестве материалов с ГПУ решеткой были использованы титановые сплавы Ti-6Al-4Mо (ВСМПОАВИСМА, Верхняя Салда) химического состава, мас.\%: Ti-5.7Al-3.8Mo-1.2Zr-1.3Sn-0.16Fe и Ti-6Al-4V химического состава, мас.\%: Ti-5.95V-5.01Al. Сплавы исследовали в исходном (горячекатаном) КЗ состоянии, а также в УМ3 состоянии. Сплав Ti-6Al-4Mo для получения УМЗ состояния подвергали термообработке (ТО) путем нагревания до температуры $940^{\circ} \mathrm{C}$, последующей закалки в воде, отжига в течение часа при $700^{\circ} \mathrm{C}$ и охлаждения на воздухе для получения глобулярно-пластинчатой структуры. Затем проводили ротационную ковку (РК) [17] при температуре $750^{\circ} \mathrm{C}, e \approx 1.7, V_{\text {деф. }}$ выше 300 мм $\mathrm{c}^{-1}$. УМ3 состояние сплава Ti-6Al-4V было получено путем РКУП и РКУП + изотермическая осадка (ИЗТО) [18,19]. РКУП проводили по режиму: заготовку из сплава подвергали гомогенизационному отжигу. Затем проводили закалку в воде от температуры $960^{\circ} \mathrm{C}+$ отпуск при $675^{\circ} \mathrm{C}$ в течение 4 часов + РКУП при $650^{\circ} \mathrm{C}$ (маршрут $\mathrm{B}_{c}, \quad n=6, \varphi=120^{\circ}$ ). После РКУП часть заготовок подвергали ИЗТО при $T=750^{\circ} \mathrm{C}, \varepsilon=30 \%$ (предварительный нагрев штампа и заготовки составлял 30 минут), скорость деформации $10^{-2} \mathrm{c}^{-1}$.

Исследование тонкой структуры сплавов проводили в просвечивающем электронном микроскопе (ПЭМ) JEOL JEM-2100. Испытания сплава на твердость проводили на твердомере ТН 300 . Статическое растяжение цилиндрических образцов диаметром 3 мм при температурах 20 и $-196^{\circ} \mathrm{C}$ проводили на универсальной испытательной машине Н50КТ согласно ГОСТ 1497-84 и ГОСТ 22706-77. Испытание сплава на статическую трещиностойкость $\left(K_{1 \mathrm{C}}\right)$ проводили на призматических образцах толщиной 10 мм по схеме трехточечного изгиба, согласно ГОСТ 25.506-85, в среде жидкого азота $\left(-196^{\circ} \mathrm{C}\right)$ с использованием специально разработанного дюара. Микрофрактографические исследования всех изломов проводили в растровом электронном микроскопе (РЭМ) SIGMA фирмы «ZEISS». 


\section{3. Результаты исследования и их обсуждение}

Исходная структура сплава Ti-6Al-4Мо представляла собой смешанную глобулярно-пластинчатую структуру. Средний размер первичной $\alpha$-фазы составлял 5 мкм, толщина $\alpha$ ламеллей -0.2 мкм. После РК пластинчатая составляющая сплава $\mathrm{Ti}-6 \mathrm{Al}-4 \mathrm{Mo}$ практически полностью трансформируется в глобулярную. Исследование тонкой структуры сплава показало (Рис. 1a), что после РК средний размер субзерен в результате деформации и фрагментации пластин a-фазы варьировался от 0.2 до 0.3 мкм. При этом зерна первичной $\alpha$-фазы были фрагментированы новыми субзеренными границами.

Исходная структура титанового сплава Ti-6Al-4V состояла из первичной $\alpha$-фазы в виде равноосных зерен с размером $(15 \pm 5)$ мкм и области с пластинчатой $(\alpha+\beta)$ структурой. Объемная доля глобулярной составляющей $\alpha$-фазы составляла около $65 \%$. РКУП привело к уменьшению размера первичных зерен а-фазы до 5 мкм, а доля УМЗ структуры со средним размером зерен/субзерен $а$-фазы $(0.24 \pm 0.06)$ мкм составила около $70 \%$. Микроструктура после РКУП + ИЗТО характеризуется зернами/субзернами равноосной формы со средним размером $(0.52 \pm 0.06)$ мкм. Плотность дислокаций заметно ниже по сравнению с состоянием после РКУП, что связано с перераспределением дислокаций вследствие процессов возврата.
Таким образом, УМ3 титановые сплавы Ті-6Al-4Mo и Ti-6Al-4V являются двухфазными, однако количество второй фазы с ОЦК решеткой не превышает $8 \%$. Поэтому в дальнейшем будем рассматривать их как материалы преимущественно с ГПУ решеткой.

Из Табл. 1 видно, что формирование УМЗ структуры в сплавах по вышеуказанным схемам и режимам, за счет высокой плотности дефектов кристаллического строения, повышает твердость и прочностные свойства сплавов при растяжении, но снижает пластичность по отношению к КЗ состоянию. Понижение температуры испытания до $-196^{\circ} \mathrm{C}$ дополнительно повышает прочностные свойства сплавов, незначительно снижая пластичность.

Испытания образцов из сплавов Ti-6Al-4Mo и Ti-6Al-4V на статическую трещиностойкость показали, что УМЗ сплавы обладают более низким значением $K_{1 C^{\prime}}$ чем сплавы в КЗ состоянии (Табл. 2). Причем, согласно критерию $t /\left(K_{1 \mathrm{C}} / \sigma_{0.2}\right)^{2}>2.5[1,2]$ все образцы разрушились в условиях ПД. Однако согласно критерию $h_{\max } / t<10^{-2}$ в условиях ПД разрушились только образцы с УМЗ структурой (Табл. 2).

Как было отмечено выше, наиболее объективную информацию о локальном напряженном состоянии материала (согласно положению механики разрушения) дает анализ размеров и формы пластических зон. В условиях ПД распространение трещины сопровождается образованием у ее вершины одной

Табл. 1. Механические свойства сплавов при температурах $20^{\circ} \mathrm{C} /-196^{\circ} \mathrm{C}$.

Table 1. Mechanical properties of alloys at temperatures of $20^{\circ} \mathrm{C} /-196^{\circ} \mathrm{C}$.

\begin{tabular}{|c|c|c|c|c|c|}
\hline $\begin{array}{l}\text { Сплав } \\
\text { Alloy }\end{array}$ & $\begin{array}{c}\text { Состояние } \\
\text { State } \\
\end{array}$ & $\mathrm{HB}$ & $\begin{array}{l}\sigma_{\mathrm{B}}, \mathrm{M \Pi а} \\
\sigma_{\mathrm{TS}}, \mathrm{MPa}\end{array}$ & $\begin{array}{l}\sigma_{0.2}, \mathrm{M} \Pi \mathrm{a} \\
\sigma_{0.2}, \mathrm{MPa}\end{array}$ & $\delta, \%$ \\
\hline \multirow{2}{*}{ Ti-6Al-4Mo } & $\begin{array}{l}\text { К3 (исходное) } \\
\text { CG (Initial) }\end{array}$ & 331 & $1017 \pm 20 / 161 \pm 10$ & $949 \pm 25 / 1505 \pm 20$ & $16 \pm 0.4 / 13.5 \pm 1.7$ \\
\hline & $\begin{array}{l}\text { YM3 (PK) } \\
\text { UFG (RF) }\end{array}$ & 352 & $1216 \pm 10 / 1802 \pm 5$ & $1137 \pm 15 / 1685 \pm 10$ & $11 \pm 1.3 / 10.1 \pm 0.8$ \\
\hline \multirow{3}{*}{ Ti-6Al-4V } & $\begin{array}{c}\text { К3 (исходное) } \\
\text { CG (Initial) }\end{array}$ & 331 & $950 \pm 20 / 1577 \pm 10$ & $849 \pm 20 / 1476 \pm 15$ & $12 \pm 1.4 / 11 \pm 1.3$ \\
\hline & $\begin{array}{l}\text { УМЗ (РКУП) } \\
\text { UFG (ЕСАР) }\end{array}$ & 341 & $1090 \pm 15 / 1770 \pm 10$ & $990 \pm 10 / 1723 \pm 5$ & $8 \pm 0.8 / 7 \pm 0.5$ \\
\hline & $\begin{array}{c}\text { УМЗ (РКУП + ИЗТО) } \\
\text { UFG (ЕСАР + IF) }\end{array}$ & 352 & $1100 \pm 15 / 1774 \pm 5$ & $1090 \pm 15 / 1745 \pm 10$ & $8 \pm 1.2 / 6.8 \pm 0.7$ \\
\hline
\end{tabular}

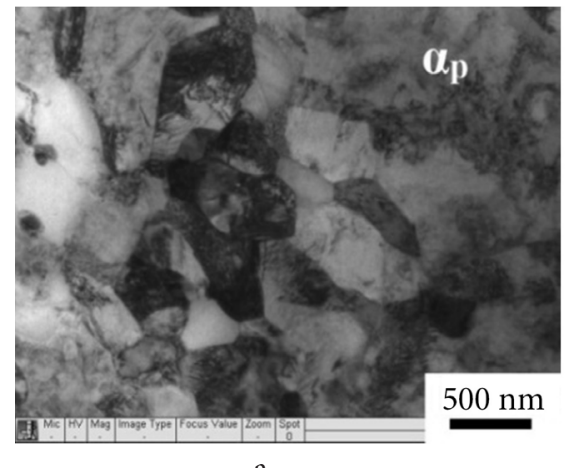

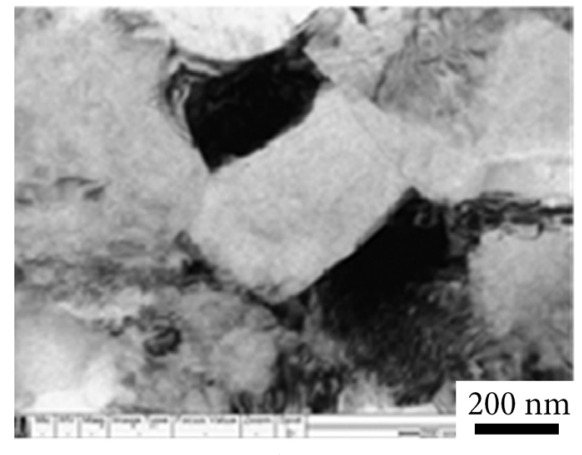

$\mathrm{b}$

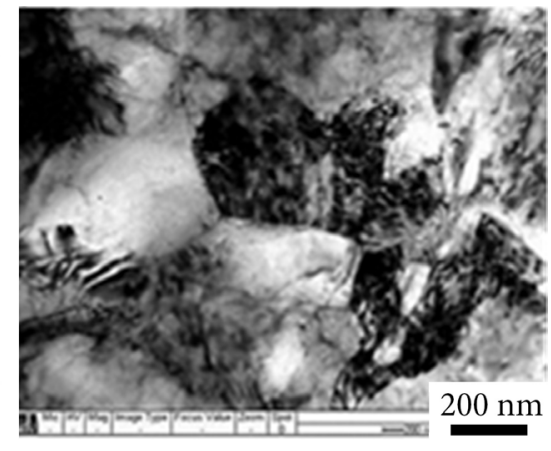

Рис. 1. Тонкая структура сплава Ti-6Al-4Mо после ротационной ковки (РК) (a), а также сплава Ti-6Al-4V после РКУП (b) и после РКУП + изотермической осадки (ИЗТО) (c).

Fig. 1. The fine structure of the alloy Ti-6Al-4Mo after the rotary forging (RF) (a), and the alloy Ti-6Al-4V after ECAP (b) and also after ECAP + isothermal forging (IF) (c). 
пластической зоны; из-за небольших размеров зоны отношение $h_{\max } / t<10^{-2}$. Именно эти два фактора, наряду с отсутствием утяжки вблизи излома и прямолинейный вид диаграммы «нагрузка-растяжение», по нашему мнению, дают основание утверждать, что разрушение произошло именно в условиях ПД.

Рассмотрим связь критерия $h_{\max } / t$ с известным критерием $t /\left(K_{1 \mathrm{C}} / \sigma_{0.2}\right)^{2}$ для К3 и УМЗ сплавов $\mathrm{Ti}-6 \mathrm{Al}-4 \mathrm{Mo}$ и Ti-6Al-4V в сравнении со аналогичной связью некоторых материалов с ОЦК и ГЦК решеткой, представленных в работах $[15,16]$ (Рис. 2). Из Рис. 2 видно, что графическая зависимость, отражающая связь критериев $t /\left(K_{1 \mathrm{C}} / \sigma_{0.2}\right)^{2}$ и $h_{\max } / t$ для титановых сплавов с ГПУ решеткой хорошо совпадает с данной зависимостью для материалов с ГЦК решеткой.

Из анализа приведенного рисунка можно сделать следующие выводы.

1. Критерий реализации условия ПД $t /\left(K / \sigma_{0.2}\right)^{2} \geq 2.5$ $[1,2,7]$ (на графике отмечен вертикальной линией) для сплавов с ГПУ решеткой является менее жестким, чем критерий $h_{\max } / t<10^{-2}$ и включает в себя часть переходной области (ПДњПН).

Табл. 2. Статическая трещиностойкость $\left(K_{1 \mathrm{C}}, K_{\mathrm{C}}\right)$ сплавов, глубина микро- $\left(h_{y h}\right)$ и макрозоны $\left(h_{y}\right)$ под поверхностью изломов и критерии локального наряженного состояния $t /\left(K_{1 \mathrm{C}} / \sigma_{0.2}\right)^{2}$ и $h_{\max } / t$.

Table 2. Static crack resistance $\left(K_{1 \mathrm{C}}, K_{\mathrm{C}}\right)$ of alloys, micro $\left(h_{y h}\right)$ and macrozone $\left(h_{y}\right)$ depths under the fracture surface, criteria of the local stress state $t /\left(K_{1 \mathrm{C}} / \sigma_{0.2}\right)^{2}$ and $h_{\max } / t$.

\begin{tabular}{|c|c|c|c|c|c|c|}
\hline $\begin{array}{l}\text { Сплав } \\
\text { Alloy }\end{array}$ & $\begin{array}{l}\text { Состояние } \\
\text { State }\end{array}$ & $\begin{array}{l}K_{1 \mathrm{C}}\left(K_{\mathrm{C}}\right), \mathrm{M \Pi a} \sqrt{\mathrm{M}} \\
K_{\mathrm{1C}}\left(K_{\mathrm{C}}\right), \mathrm{MPa} \sqrt{\mathrm{m}}\end{array}$ & $\begin{array}{c}t /\left(K_{1 \mathrm{C}} / \sigma_{0.2}\right)^{2} / \text { ПД, ПН } \\
t /\left(K_{1 \mathrm{C}} / \sigma_{0.2}\right)^{2} / \mathrm{PD}, \mathrm{PS}\end{array}$ & $\begin{array}{l}h_{y h}, 10^{-5} \mathrm{M} \\
h_{y h}, 10^{-5} \mathrm{~m}\end{array}$ & $\begin{array}{l}h_{y}, 10^{-5} \mathrm{M} \\
h_{y}, 10^{-5} \mathrm{~m}\end{array}$ & $\begin{array}{c}h_{\max } / t / \text { ПД, ПН } \\
h_{\max } / t / \mathrm{PD}, \mathrm{PS}\end{array}$ \\
\hline \multirow{2}{*}{ Ti-6Al-4Mo } & $\begin{array}{c}\text { К3 (исходное) } \\
\text { CG (Initial) }\end{array}$ & $48 \pm 0.66$ & $\begin{array}{l}9.8 / \text { П } \\
9.8 / \text { РD }\end{array}$ & - & 10.0 & $\begin{array}{c}10^{-2} / \Pi Д \leftrightarrow \text { ПН } \\
10^{-2} / \mathrm{PD} \leftrightarrow \mathrm{PS}\end{array}$ \\
\hline & $\begin{array}{l}\text { YM3 (PK) } \\
\text { UFG (HR) }\end{array}$ & $34 \pm 0.68$ & $\begin{array}{l}24.6 / \text { ПД } \\
24.6 / \text { РD }\end{array}$ & - & 5.0 & $\begin{array}{l}5.0 \cdot 10^{-3} / \text { ПД } \\
5.0 \cdot 10^{-3} / \mathrm{PD}\end{array}$ \\
\hline \multirow{3}{*}{ Ti-6Al-4V } & $\begin{array}{c}\text { К3 (исходное) } \\
\text { CG (Initial) } \\
\end{array}$ & $48 \pm 1.9$ & $\begin{array}{l}9.5 / \text { ПД } \\
9.5 / \text { PD }\end{array}$ & 3.0 & 11.5 & $\begin{array}{c}1.2 \cdot 10^{-2} / \Pi Д \leftrightarrow \Pi Н \\
1.2 \cdot 10^{-2} / \mathrm{PD} \leftrightarrow \mathrm{PS}\end{array}$ \\
\hline & $\begin{array}{l}\text { УМЗ (РКУП) } \\
\text { UFG (ЕСАР) }\end{array}$ & $34 \pm 1.0$ & $\begin{array}{l}26 / \text { ПД } \\
26 / \mathrm{PD}\end{array}$ & - & 4.0 & $\begin{array}{l}4.0 \cdot 10^{-3} / \text { ПД } \\
4.0 \cdot 10^{-3} / \mathrm{PD}\end{array}$ \\
\hline & $\begin{array}{c}\text { УМЗ (РКУП + ИЗТО) } \\
\text { UFG (ЕСАР + IS) }\end{array}$ & $28 \pm 1.0$ & $\begin{array}{l}36 / \text { П } \\
36 / \mathrm{PD}\end{array}$ & - & 2.0 & $\begin{array}{l}2.0 \cdot 10^{-3} / \text { ПД } \\
2.0 \cdot 10^{-3} / \mathrm{PD}\end{array}$ \\
\hline
\end{tabular}

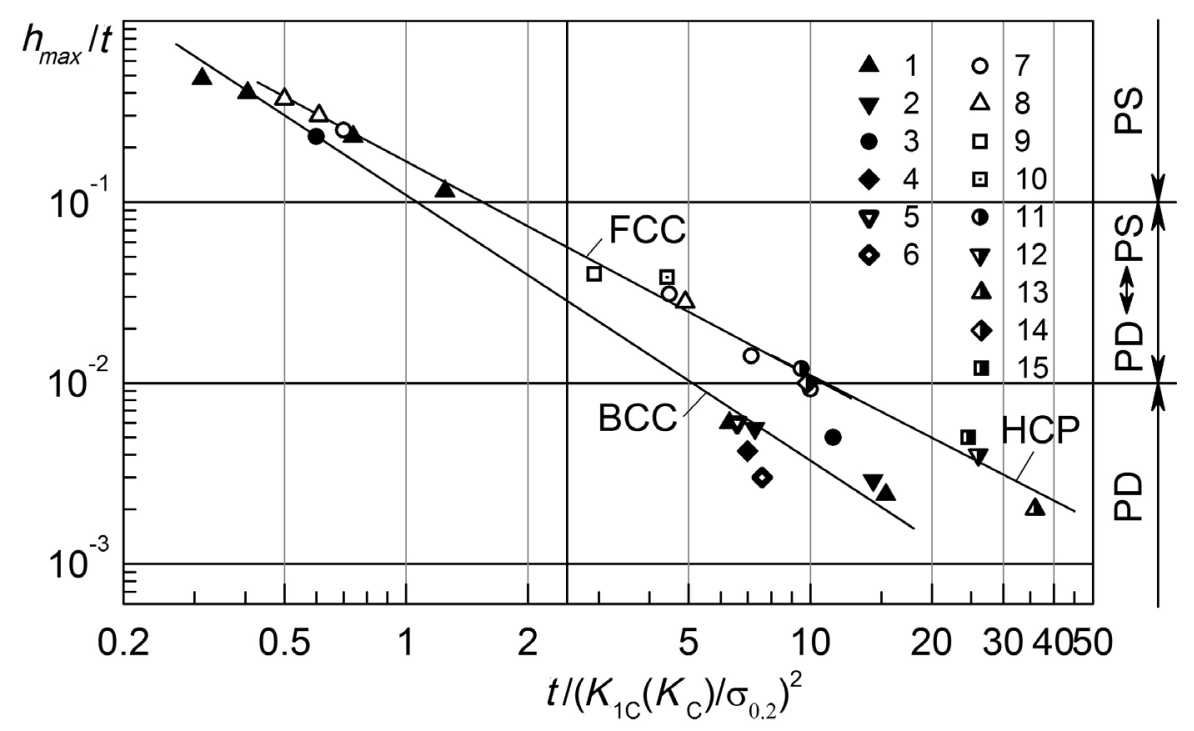

Рис. 2. Связь критериев $t /\left(K_{1 \mathrm{c}} / \sigma_{0.2}\right)^{2}$ и $h_{\text {max }} / t$ для материалов с ОЦК решеткой (темные точки), ГЦК решеткой (светлые точки) и ГПУ решеткой (комбинированные точки) в КЗ состоянии $(1-4,7-9,11,14)$ и в УМЗ состоянии $(5,6,10,12,13,15)$. Вертикальная линия соответствует критерию $t /\left(K_{1 \mathrm{C}} / \sigma_{0.2}\right)^{2} \geq 2.5$.

1 - С20; 2 - C40; 3 - Fe-0.15C-2Cr-1Mo-1V; 4 - 9MnSi5; 5 - C45 (РКУП); 6 - 9MnSi5 (РКУП); 7 - ENAW-2024; 8 - Fe-0.03C-13Cr-0.1N-19Mn; 9 - ENAW-2618A; 10 - ENAW-2618A (РКУП); 11 - Ti-6Al-4V; 12 - Ti-6Al-4V (РКУП); 13 - Тi-6Al-4V (РКУП + ИЗТО); 14 - Ti-6Al-4Mo; 15 - Ti-6Al-4Mo (РК).

Fig. 2. Relationship of the $t /\left(K_{1 \mathrm{C}} / \sigma_{0.2}\right)^{2}$ and $h_{\max } / t$ criteria for materials in the bcc lattice (dark dots), fcc lattice (light dots) and hcp lattice (combined dots) in CG state $(1-4,7-9,11,14)$ and also in the UFG state $(5,6,10,12,13,15)$. The vertical line meets the criterion $t /\left(K_{1 \mathrm{C}} / \sigma_{0.2}\right)^{2} \geq 2.5$.

1 - C20; 2 - C40; 3 - Fe-0.15C-2Cr-1Mo-1V; 4 - 9MnSi5; 5 - C45 (ECAP); 6 - 9MnSi5 (ECAP); 7 - ENAW-2024; 8 - Fe-0.03C-13Cr-0.1N-19Mn; 9 - ENAW-2618A; 10 - ENAW-2618A (ECAP); 11 - Ti-6Al-4V; 12 - Ti-6Al-4V (ECAP); 13 - Ti-6Al-4V (ECAP + IF); $14-$ Ti-6Al-4Mo; 15 - Ti-6Al-4Mo (RF). 
2. При определении условий ПД с использованием критерия $t /\left(K_{1 C} / \sigma_{0.2}\right)^{2}$ необходимо учитывать тип кристаллической решетки материала. Для материалов с ГПУ решеткой, также как и для материалов с ГЦК решеткой, условие ПД можно записать в виде $t /\left(K_{1 \mathrm{C}} / \sigma_{0.2}\right)^{2} \geq 10$. Для материалов с ОЦК решеткой, как было показано в работах $[15,16]$, данное условие выполняется при $t /\left(K_{1 \mathrm{C}} / \sigma_{0.2}\right)^{2} \geq 5$. Причем данное положение справедливо как для КЗ, так и для УМЗ сплавов.

3 . Критерий $h_{\text {max }} / t$ позволяет при диагностике причин аварийного разрушения конструкций и деталей машин количественно сопоставить локальное напряженное состояние материала, в разрушенной детали и имитирующем образце во всем интервале от ПД к ПН.

Вышеуказанное различие в критериях реализации условий ПД для материалов с различным типом кристаллической решетки связано, по-видимому, с наличием вязко-хрупкого перехода в материалах с ОЦК решеткой и отсутствием такового в материалах с ГЦК и ГПУ решеткой, а, следовательно, и различных механизмах разрушения в условиях ПД. Материалы с ОЦК решеткой в условиях ПД разрушаются по механизму скола или квазискола (Рис. 3 a), материалы с ГЦК решеткой - по смешанному механизму, а микрорельеф изломов сплавов с ГПУ решеткой состоит из хаотично расположенных сравнительно гладких гребней (Рис. 3 b, с). Аналогичный микрорельеф авторы ранее наблюдали при ударном разрушении титана Grade 4 (ГПУ решетка) [20].

Морфология поверхности изломов титана и титановых сплавов, а также сильная локализация пластической деформации у поверхности таких изломов при отсутствии утяжки и наличие одной пластической зоны под поверхностью изломов указывают, по мнению авторов, на иной механизм формирования микрорельефа, отличного от механизма формирования ямочного микрорельефа при вязком разрушении.

\section{4. Выводы}

Условие реализации плоской деформации ПД по критерию $t /\left(K_{1 \mathrm{C}} / \sigma_{0.2}\right)^{2} \geq 2.5$ для сплавов с ГПУ решеткой является менее жестким, чем по критерию $h_{\max } / t<10^{-2}$ и включает в себя часть переходной области (ПД $\leftrightarrow$ ПН).
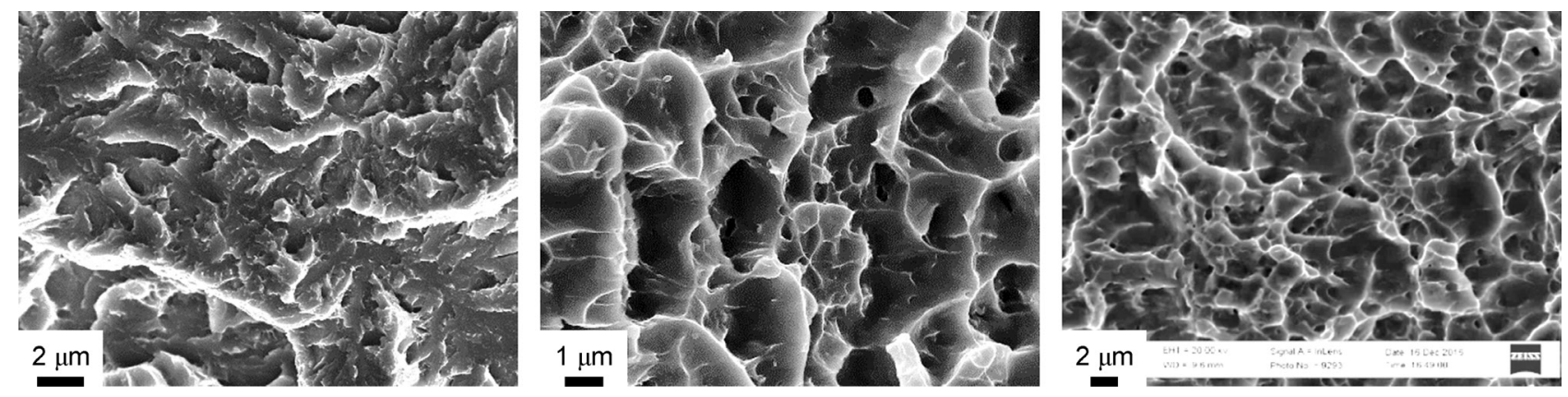

Рис. 3. Микрорельеф статических изломов образцов из УМЗ материалов с ОЦК решеткой (С45) [8] (a) и сплавов с ГПУ решеткой: Ti-6Al-4Mo (b) и Ti-6Al-4V (c). (a, c) - x2000; (b) - x8000.

Fig. 3. The microrelief of static fractures of samples from UFG materials with bcc lattice (C45) [8] (a) and alloys with hcp lattice: Ti-6Al-4Mo (b) and Ti-6Al-4V (c). (a, c) - x2000; (b) - x8000. 
металлических материалов. Уфа, УГАТУ (2016) 240 с.]

7. A.J. McEvily. Metal Failures: Mechanisms, Analysis, Prevention. New York, Wiley \& Sons (2002) 324 p.

8. G. V. Klevtsov, L. R. Botvina, N. A. Klevtsova, L. V. Limar. Fraktodiagnostika razrusheniya metallicheskikh materialov i konstruktsiy. Moscow, MISiS (2007) 264 p. (in Russian) [Г. В. Клевцов, Л. Р. Ботвина, Н.А.Клевцова, Л.В. Лимарь. Фрактодиагностика разрушения металлических материалов и конструкций. Москва, МИСиС (2007) 264 с.]

9. L. C.Moroz. Mekhanika ifizika deformatsiyi razrusheniya. Leningrad, Engineering (1984) 224 p. (in Russian) [Л.С. Мороз. Механика и физика деформаций и разрушения. Ленинград, Машиностроение (1984) 224 c.]

10. V.I. Vladimirov. Fizicheskaya priroda razrusheniya materialov. Moscow, Metallurgy (1984) 280 p. (in Russian) [В.И. Владимиров. Физическая природа разрушения материалов. Москва, Металлургия (1984) 280 с.]

11. L. R. Botvina, N.A. Klevtsova, A.P. Fot. Metal Science and Heat Treatment. 52 (7), 396 (2010).

12. G. V. Klevtsov, L.R. Botvina, N.A. Klevtsova. ISIJ International. 36 (2), 222 (1996). Crossref

13. N. A.Klevtsova, O. A. Frolova, G. V.Klevtsov. Razrusheniye austenitnykh staley i martensitnyye prevrashcheniya $\mathrm{v}$ plasticheskikh zonakh. Moscow, AE (2005) 155 p. (in Russian) [Н. А. Клевцова, О.А.Фролова, Г.В.Клевцов. Разрушение аустенитных сталей и мартенситные превращения в пластических зонах. Москва, АЕ (2005) 155 c.]
14. G. V. Klevtsov, L. R. Botvina, N. A. Klevtsova. ISIJ International. 36 (2), 215 (1996). Crossref

15. G. V. Klevtsov, N. A. Klevtsova, R. Z. Valiev, I. N. Pigaleva, O.A. Frolova. Bulletin of the Tambov University. Series: Natural and Technical Sciences. 21 (3), 772 (2016) (in Russian) [Г. В. Клевцов, Н.А. Клевцова, Р.3. Валиев, И.Н. Пигалева, О.А. Фролова. Вестник Тамбовского университета. Серия: Естественные и технические науки. 21 (3), 772 (2016).] Crossref

16. G. Klevtsov, N. Klevtsova, R. Valiev, I. Pigaleva In: The International science and technical congress on Aerospace materials plastic deformation processes. Science, technology, industry (Ed. by A. M. Shterenberg). Samara, SSAU (2017) pp. 81-84.

17. ASM Handbook. Vol. 14A. Metalworking: Bulk Forming (Ed. by S.L. Semiatin). ASM International $®$. (2005) pp. 179-182. Crossref

18. R.Z. Valiev, A.P. Zhilyaev, T.G. Langdon. Bulk Nanostructured Materials: Fundamentals and Applications. TMS, WILEY (2014) 440 p. Crossref

19. Y. Estrin, A. Vinogradov. Extreme grain refinement by severe plastic deformation: A wealth of challenging science. Acta Materialia. 61,782 (2013).

20. R. Z. Valiev, G. V. Klevtsov, I. P. Semenova, N. A. Klevtsova, D.V. Gunderov, M.V. Fesenuk, M.R. Kashapov. Deformatsiya i Razrushenie materialov. 11, 32 (2012). (in Russian) [Р.3. Валиев, Г.В. Клевцов, И.П. Семенова, Н.А. Клевцова, Д.В. Гундеров, М.В. Фесенюк, M.P. Кашапов. Деформация и разрушение материалов. 11, 32 (2012).] 